\title{
Handling Increased Faculty and Student Workload During Difficult Economic Times
}

\section{Prof. Terence Geyer, Eastern Washington University}

Terence Geyer, Eastern Washington University Terence L. D. Geyer is currently a Senior Lecturer in the Department of Engineering \& Design at Eastern Washington University. He obtained his B.S. in Manufacturing Technology and M.Ed. in Adult Education in a specially combined program of Technology and Education at Eastern Washington University. He has 20 years of business experience in the IT field and 15 years of experience in education. He lives off-grid for eight months of the year using both older and newer technology. His interests include collecting and re-manufacturing older technologies.

\section{Dr. William R Loendorf, Eastern Washington University}

William R. Loendorf is a Full Professor, Emeritus of Engineering \& Design at Eastern Washington University. He obtained his B.Sc. in Engineering Science at the University of Wisconsin - Parkside, M.S. in Electrical Engineering at Colorado State University, M.B.A. at the Lake Forest Graduate School of Management, and Ph.D. in Engineering Management at Walden University. He holds a Professional Engineer license and has 30 years of industrial experience as an Engineer or Engineering Manager at General Motors, Cadnetix, and Motorola. His interests include engineering management, technological literacy, improving the competitiveness of American companies, and real-time embedded systems. 


\title{
Handling Increased Faculty and Student Workload During Difficult Economic Times
}

\begin{abstract}
The recent national economic downturn has placed increasing pressure on higher education to do more with less, or maintain program integrity with diminishing dollars. Faced with financial challenges to adding faculty, especially in light of enrollment increases, there has to be another way to meet this challenge. In conventional course occurrences, events like a midterm, final and assignments tend to overlap between classes, and can cause big spikes in student workload. With an increased number of students in each class, students can also feel the pressure of increased competition. These stresses' on both faculty and students, negatively affect the positive outcomes desired by both groups. This paper describes the formulation, design, and execution of two planning methods used to help balance the needs, workload, and time resources for both the faculty and students in an Engineering curriculum. One approach compares weekly instructor workload for the planning and delivery across three classes. Covering items from the creation of the syllabus and homework assignments, to lecture preparation and grading, its goal is to create a workable structure for the instructor. The second approach compares the actual weekly assignment and exam load across seven classes for students with when those assignments and exams need to be graded by the instructor. This method looks at the work that needs to be accomplished and sets up a structure to help insure the success of the student learning, and the instructor's ability to actually grade the work in a balanced format. Included in the paper are the actual grading workload counts for each method. The paper also challenges the reader to review his or her own instructional planning methods for possible improvements in outcomes for both students and faculty.
\end{abstract}

\section{Introduction}

The courses covered in this report give a representation of the various class instructional modes experienced by Engineering Technology students (lecture-nonmathematical, lecturemathematical, lecture/lab, lecture/discussion) and span the full range of types of student workload, as well as instructor grading demands. The project was conducted using two instructors who were attempting to gain a better control of all of the demands placed on students and faculty in our changing economic realities in higher education. In most colleges that have a high amount of transfer students, it has become increasingly more difficult to estimate enrollment numbers and program/course demand in a timely manner. While students, who are already in existing programs, are easy to count and have a propensity to register early in each quarter's cycle, it has not been easy to predict what the final numbers will be when each quarter starts. The programs/courses covered in this project have not been capped, nor has there been a limit placed on the number of sections or total enrollments that will be allowed for each quarter. Because of the demand for increasing STEM enrollment from the State level government, the University is one of the few 4-year colleges left that accept students into these programs without enrollment caps. The other major 4-year colleges within the State have been capped in their STEM programs for a number of years. When students start in those programs at the other State 
universities, they are told they are competing against the students sitting next to them in class, and, in two years, $50 \%$ of the students will have to move to another college due to enrollment capping. To be able to continue their educational goals, a large percentage of those students choose our University.

Our University has a history of attempting to accommodate as many of these students as possible. In doing so, it places increased demands on the faculty in the short-term since showing the need or increased demand for adding faculty results in a process that can take over a year to hire additional faculty. Even after proving the increased staffing requirements for handling the additional students, there is the financial challenge associated with any solution that is chosen. The use of short-term adjuncts or temporary instructors has not worked well in the past, because it was difficult to develop a pool of the properly experienced and qualified instructors. This has lead to increases in class size and workload through course overloads with the existing faculty. In conventional course occurrences, events like a midterm, final and assignments tend to overlap between classes, and can cause big spikes in student workload. With an increased number of students in each class, students can also feel the pressure of increased competition. The increase in each course's required grading also places additional stress on the faculty. These stresses' on both faculty and students, negatively affect the positive outcomes desired by both groups.

\section{Theoretical or Conceptual Support}

The faculty workload question is not a new one (Winkler $\left.{ }^{6}, 2010\right)$. It has been studied and researched for years and in many ways. In fact, the complexity of the relationships between quantity and quality of academic work has been analyzed in terms of relevant concepts and processes as well (Soliman \& Soliman ${ }^{5}$, 1997). Other studies have investigated the impact of the increasing demands on staff stress and work-life balance (Houston, Meyer, \& Paewai ${ }^{3}, 2006$ ). Some models have also been suggested to balance faculty workload (Cundy, Gibson, \& Rabern ${ }^{2}$, 2001). A number of other papers were also published on similar aspects of this subject.

When researching for planning methods that target the goals presented in this paper, there was not a large amount of currently available information that directly applies. Searching the Internet for "balancing teaching workload across multiple classes," a variety of sources will surface that use a much different interpretation. In "Balancing Faculty Workload" (American Mathematical Society ${ }^{1}$, 2012), the areas covering teaching, research, and service are the key elements of concern when it comes to the topic of teaching workload. Indeed, even in our own Engineering and Design Department, teaching workload planning is directly tied to promotion and tenure and is focused on those three main areas.

Another common area that comes up in this particular search deals directly with the information technology arena. In "MikroTik Router OS Workshop Load Balancing Best Practice" (Megis ${ }^{4}$, 2012), the concept of load-balancing is presented as a technique to distribute workload across network links as a way of maximizing throughput and avoiding overload. When thinking of the students and faculty as the network links and the throughput is the assignments, projects, and exams, a similarity of purpose can be connected. The goal of not overloading the system is a way to optimize its overall function. In reality, this concept has more in common with the goals and purposes being presented by the following planning methods. 


\section{Method 1}

The following is a description of each class, the mode and method of instruction, and the student workload for the planning method covered in this section.

TECH 320 Non-Metallic Processes is a 5-credit lecture/laboratory mode of instruction. Student workload includes: two written reports, 10 lab projects, four quizzes, a mid-term and a final.

TECH 452 Engineering Economics is a 2-credits lecture-mathematical mode of instruction. Student workload includes: seven homework assignments, a mid-term and a final.

TECH 454 Environmental Engineering is a 2-credit lecture/discussion mode of instruction. Student workload includes: five project assignments, a mid-term and a final.

The Method 1 approach compares the weekly instructor workload for the planning and delivery across three classes. Covering items from the creation of the syllabus and homework assignments, to lecture preparation and grading, its goal is to create a workable structure for the instructor, refer to Table 1, Summarized Instructor Course Planning. In this table, its course number and a shortened version of its full name are listed for each class, as well as a listing for week " 0 " through week " 11 ". Week 0 is prior to the first week of the quarter, Week 1 is the first week of the quarter, week 10 is the last week of instruction, and week 11 is the traditional finals week.

Using this method, the instructor starts the planning process before the start of the quarter, listed in the table as "Week 0". While this can be done as late as the week before class, it is recommended to be completed further in advance of this time to help the instructor gain overall control of his or her total workload. Included for each of the three classes presented are notations for updating the syllabus, the creation or updating of the homework assignments or projects, updating or preparing of the class lectures, grading of the homework assignments and projects, as well as the grading of the midterms and finals. The listings for the "Grade Count" gives the total number of items that need to be graded for that specific class for each week, and whether the item is a turned-in homework, project, midterm, or final. The "Total Grade" column shows the total grading that the instructor will be required to grade for each of the listed weeks.

Looking at the workload, from the instructor's viewpoint, the grading aspect does not begin until the end of the second week of the quarter. Then, it increases and peaks in week six and again at the end of week ten. For the classes covered in this method, the finals occurred during the last scheduled class day during week 10. These peaks can task even the best of any instructor's ability to be able to handle them. For the student, their workload peaks would occur just prior to the instructors grading requirements. Traditionally, in the Engineering and Design Department, this method would be representative of what was historically happening in our overall class workload structure. Faculty would get together and talk about the overall workload, and commensurate about the difficulty of handling the workload peaks, often wishing that there was a better way. 
Table 1, Summarized Instructor Course Planning

\begin{tabular}{|c|c|c|c|c|c|c|c|}
\hline Week & $\begin{array}{l}\text { TECH } 452 \\
\text { Economics }\end{array}$ & $\begin{array}{l}\text { Grade } \\
\text { Count }\end{array}$ & $\begin{array}{c}\text { TECH } 454 \\
\text { Environment }\end{array}$ & $\begin{array}{l}\text { Grade } \\
\text { Count }\end{array}$ & $\begin{array}{c}\text { TECH } 320 \\
\text { Non-Metallics }\end{array}$ & $\begin{array}{l}\text { Grade } \\
\text { Count }\end{array}$ & $\begin{array}{l}\text { Total } \\
\text { Grade }\end{array}$ \\
\hline 0 & $\begin{array}{l}\text { Update Syllabus } \\
\text { Create HW } 1 \\
\text { Prep Lecture } 1 \\
\end{array}$ & & $\begin{array}{l}\text { Update Syllabus } \\
\text { Check Project } 1 \\
\text { Update Lecture 1,2 }\end{array}$ & & $\begin{array}{l}\text { Update Syllabus } \\
\text { Prep Lecture 1,2 } \\
\text { Update Report }\end{array}$ & & \\
\hline 1 & $\begin{array}{l}\text { First Class } \\
\text { Create HW } 2 \\
\text { Prep Lecture } 2\end{array}$ & & $\begin{array}{l}\text { First Class } \\
\text { Check Project } 2 \\
\text { Update Lecture } 3\end{array}$ & & $\begin{array}{l}\text { First Class } \\
\text { Prep Lecture 3,4 } \\
\text { Create Quiz } 1 \\
\end{array}$ & & \\
\hline 2 & $\begin{array}{l}\text { Create HW } 3 \\
\text { Prep Lecture } 3 \\
\text { Check Midterm }\end{array}$ & & $\begin{array}{l}\text { Check Project } 3 \\
\text { Grade Project } 1 \\
\text { Update Lecture } 4\end{array}$ & 33 & $\begin{array}{l}\text { Grade Quiz } 1 \\
\text { Prep Lecture } 6\end{array}$ & 31 & 64 \\
\hline 3 & $\begin{array}{l}\text { Create HW } 4 \\
\text { Grade HW } 1 \\
\text { Prep Lecture } 4\end{array}$ & 32 & $\begin{array}{l}\text { Check Midterm } \\
\text { Grade Project } 2 \\
\text { Update Lecture } 5\end{array}$ & 33 & $\begin{array}{l}\text { Prep Lecture 7,8 } \\
\text { Create Quiz } 2\end{array}$ & & 65 \\
\hline 4 & $\begin{array}{l}\text { Create HW } 5 \\
\text { Grade HW } 2 \\
\text { Prep Lecture } 5\end{array}$ & 32 & $\begin{array}{l}\text { Grade Project } 3 \\
\text { Update Lecture } 6\end{array}$ & 33 & $\begin{array}{l}\text { Prep Lecture } 10 \\
\text { Grade Quiz } 2\end{array}$ & 31 & 96 \\
\hline 5 & $\begin{array}{l}\text { Create HW } 6 \\
\text { Grade HW } 3 \\
\text { Prep Lecture } 6\end{array}$ & 32 & $\begin{array}{l}\text { Check Project } 4 \\
\text { Update Lecture } 7\end{array}$ & & $\begin{array}{l}\text { Prep Lecture } \\
11,12 \\
\text { Grade Reports } \\
\text { Create Quiz } 3\end{array}$ & 62 & 94 \\
\hline 6 & $\begin{array}{l}\text { Grade Midterm } \\
\text { Grade HW } 4 \\
\text { Prep Lecture } 7\end{array}$ & $\begin{array}{l}32 \\
32\end{array}$ & $\begin{array}{l}\text { Check Project } 5 \\
\text { Grade Midterm } \\
\text { Update Lecture } 8\end{array}$ & 33 & $\begin{array}{l}\text { Grade Midterm } \\
\text { Prep Lecture } 13\end{array}$ & 31 & 128 \\
\hline 7 & $\begin{array}{l}\text { Create HW } 6 \\
\text { Grade HW } 5 \\
\text { Prep Lecture } 8\end{array}$ & 32 & Grade Project 4 & 33 & $\begin{array}{l}\text { Prep Lecture } \\
15,16 \\
\text { Grade Quiz } 3\end{array}$ & 31 & 96 \\
\hline 8 & $\begin{array}{l}\text { Create HW } 7 \\
\text { Grade HW } 6 \\
\text { Prep Lecture } 9\end{array}$ & $\begin{array}{l}32 \\
32\end{array}$ & $\begin{array}{l}\text { Check Final } \\
\text { Update Lecture } 9\end{array}$ & & $\begin{array}{l}\text { Prep Lecture } \\
17,18 \\
\text { Create Quiz } 4\end{array}$ & & 64 \\
\hline 9 & $\begin{array}{l}\text { Grade HW } 7 \\
\text { Prep Lecture } 10\end{array}$ & 32 & $\begin{array}{l}\text { Grade Project } 5 \\
\text { Update Lecture } 10\end{array}$ & 33 & $\begin{array}{l}\text { Prep Lecture } 19 \\
\text { Grade Quiz } 4\end{array}$ & 31 & 65 \\
\hline 10 & $\begin{array}{l}\text { Final Class } \\
\text { Grade Final }\end{array}$ & 32 & $\begin{array}{l}\text { Final Class } \\
\text { Grade Final }\end{array}$ & 33 & $\begin{array}{l}\text { Final Class } \\
\text { Grade Final } \\
\text { Grade Projects }\end{array}$ & $\begin{array}{c}31 \\
310 \\
\end{array}$ & 406 \\
\hline 11 & Post Grades & 32 & Post Grades & 33 & Post Grades & 31 & 96 \\
\hline
\end{tabular}




\section{Method 2}

The following is a description of each class, the mode and method of instruction, and the student workload for the planning method covered in this section.

TECH 320 Non-Metallic Processes is a 5-credit lecture/laboratory mode of instruction. Student workload includes: two written reports, 10 lab projects, and four exams.

TECH 330 Technology Problem Analysis and Design I is a 3-credit lecture/discussion mode of instruction. Student workload includes: six written assignments.

TECH 393 Technology in World Civilization is a 4-credit traditional lecture-nonmathematical course. Student workload includes: four written assignments and four exams.

TECH 403 Computer-Aided Design and Project Management is a 4-credit consists of both lecture and laboratory/demonstration periods. The laboratory/demonstration periods are interspersed with the lecture periods. Student workload includes: seven project assignments.

TECH 452 Engineering Economics is a 2-credits lecture-mathematical mode of instruction. Student workload includes: seven homework assignments

TECH 454 Environmental Engineering is a 2-credit lecture/discussion mode of instruction. Student workload includes: five project assignments.

TECH 495 Internship is a 1 to 10 -credit variable course with a mid-term and final evaluations and reviews.

The Method 2 approach compares the weekly instructor workload for both the students and grading for the instructors across seven classes. Covering items from when the students are given the assignments, projects, and exams to when these items are graded by the instructor. Table 2 , Summarized Student/Instructor Course Assignment Planning, covers the assignments and projects. In this table, just the course numbers are listed for each class, as well as a listing for week " 1 " through week " 11 ". Week 1 is the first week of the quarter, week 10 is the last week of instruction, and week 11 is the traditional finals week.

In this table, the "Num" column for each class lists when the specific assignment (or project) is given to the students for each class. The "Due" column lists when the instructor would be required to grade each of those two items. At the bottom of the table, "TS:" lists the total number of students in each class, while the "Total Grading:" would state the total number of items to be graded by the instructor for each class by the end of the quarter (total students times total number of assignments and projects). 
Table 2, Summarized Student/Instructor Course Assignment Planning

\begin{tabular}{|c|c|c|c|c|c|c|c|c|c|c|c|c|c|c|}
\hline \multirow{2}{*}{$\begin{array}{l}\text { Assmt } \\
\text { Week }\end{array}$} & \multicolumn{2}{|l|}{ TECH 320} & \multicolumn{2}{|c|}{ TECH 330} & \multicolumn{2}{|c|}{ TECH 393} & \multicolumn{2}{|c|}{ TECH 403} & \multicolumn{2}{|c|}{ TECH 452} & \multicolumn{2}{|c|}{ TECH 454} & \multicolumn{2}{|c|}{ TECH 495} \\
\hline & Num & Due & Num & Due & Num & Due & Num & Due & Num & Due & Num & Due & Num & Due \\
\hline 1 & 1,2 & & & & & & & & & & & & 1,2 & \\
\hline 2 & 3,4 & & 1 & & 1 & & 1 & & & & 1 & & & \\
\hline 3 & 5,6 & & & 1 & & & 2 & 1 & 1 & & 2 & 1 & & \\
\hline 4 & 7,8 & & 2 & & 2 & 1 & 3 & 2 & 2 & 1 & 3 & 2 & & \\
\hline 5 & & 1,2 & 3 & 2 & & & 4 & 3 & 3 & 2 & & 3 & & 1 \\
\hline 6 & 9,10 & & 4 & 3 & 3 & 2 & 5 & 4 & 4 & 3 & 4 & & & \\
\hline 7 & 11,12 & & & 4 & & & & & 5 & 4 & & & & \\
\hline 8 & & & 5 & & 4 & 3 & 6 & 5 & 6 & 5 & 5 & 4 & & \\
\hline 9 & & & 6 & 5 & & & 7 & 6 & 7 & 6 & & & & \\
\hline 10 & & & & 6 & & 4 & & 7 & & 7 & & 5 & & 2 \\
\hline 11 & & $3 / 12$ & & & & & & & & & & & & \\
\hline TS: & 32 & & 30 & & 29 & & 40 & & 37 & & 38 & & 14 & \\
\hline & $\begin{array}{r}\text { Total } \\
\text { Grading: }\end{array}$ & 384 & & 180 & & 116 & & 280 & & 259 & & 190 & & 28 \\
\hline
\end{tabular}

In Table 3, Summarized Student/Instructor Course Exam Planning, the two classes from the group of seven that have exams are shown. In this table, just the course numbers are listed for each class, as well as a listing for week " 1 " through week " 11 ". Week 1 is the first week of the quarter, week 10 is the last week of instruction, and week 11 is the traditional finals week.

Table 3, Summarized Student/Instructor Course Exam Planning

\begin{tabular}{|c|c|c|c|c|}
\hline Exams & \multicolumn{2}{|c|}{ TECH 320 } & \multicolumn{2}{c|}{ TECH 393 } \\
Week & Num & Grade & \multicolumn{2}{c|}{ Num } \\
\hline 1 & & & & \\
\hline 2 & 1 & & & \\
\hline 3 & & 1 & 1 & \\
\hline 4 & 2 & & & 1 \\
\hline 5 & & 2 & 2 & \\
\hline 6 & & & & 2 \\
\hline 7 & 3 & & & \\
\hline 8 & & 3 & 3 & \\
\hline 9 & & & & 3 \\
\hline 10 & 4 & & 4 & \\
\hline 11 & & 4 & & 4 \\
\hline TS: & 32 & & 29 & \\
\hline & $\begin{array}{c}\text { Total } \\
\text { Grading: }\end{array}$ & 128 & & 116 \\
\hline
\end{tabular}


In this table, the "Num" column for each class lists when the specific exam is given to the students for each class. The "Grade" column lists when the instructor would be required to grade each exam. At the bottom of the table, "TS:" lists the total number of students in each class, while the "Total Grading:" would state the total number of items to be graded by the instructor for each class by the end of the quarter (total students times total number of assignments and projects).

Moving on to Table 4, Student Assignments/Exams by Week, all of the class assignments totals are added together, as listed by the week from Table 2, Summarized Student/Instructor Course Assignment Planning with all of the exams, as listed by week from Table 3, Summarized Student/Instructor Course Exam Planning. In this table, just the total of the assignments and exams are listed for each week, with a listing for week " 1 " through week " 10 ". Week 1 is the first week of the quarter, and week 10 is the last week of instruction.

Table 4, Student Assignments/Exams by Week

\begin{tabular}{|c|c|c|c|}
\hline $\begin{array}{l}\text { Student } \\
\text { Assignments/Exams }\end{array}$ & & & \\
\hline Week & $\begin{array}{l}\text { Total } \\
\text { Assmt }\end{array}$ & $\begin{array}{l}\text { Total } \\
\text { Exams }\end{array}$ & $\begin{array}{c}\text { Weekly } \\
\text { Total }\end{array}$ \\
\hline 1 & 4 & 0 & 4 \\
\hline 2 & 6 & 1 & 7 \\
\hline 3 & 5 & 1 & 6 \\
\hline 4 & 7 & 1 & 8 \\
\hline 5 & 3 & 1 & 4 \\
\hline 6 & 7 & 0 & 7 \\
\hline 7 & 3 & 1 & 4 \\
\hline 8 & 5 & 1 & 6 \\
\hline 9 & 3 & 0 & 3 \\
\hline 10 & 0 & 2 & 2 \\
\hline Totals: & 43 & 8 & 51 \\
\hline
\end{tabular}

In this table, the "Total Assmt" column for each week lists when all of the assignments are given to the students. The "Total Exams" column for each week lists when all of the exams are given to the students. The "Weekly Total" shows the combined totals. The "Totals:" at the bottom of this table shows the combined item totals for the students by the end of the quarter.

Moving on to Table 5, Instructor Grading Assignments/Exams by Week, we add together all of the students assignments and projects with the exams that need to be graded on a weekly basis. In this table, just the total of the assignments and exams are listed for each week, with a listing for week " 1 " through week " 10 ". Week 1 is the first week of the quarter, week 10 is the last week of instruction, and week 11 is the traditional finals week. 
Table 5, Instructor Grading Assignments/Exams by Week

\begin{tabular}{|c|c|c|c|}
\hline $\begin{array}{c}\text { Instructor Grading } \\
\text { Assignment/Exams }\end{array}$ & \multicolumn{2}{|c|}{} \\
\hline Week & $\begin{array}{c}\text { Total } \\
\text { Asmt }\end{array}$ & $\begin{array}{c}\text { Total } \\
\text { Exams }\end{array}$ & $\begin{array}{c}\text { Weekly } \\
\text { Total }\end{array}$ \\
\hline 1 & 0 & 0 & 0 \\
\hline 2 & 0 & 0 & 0 \\
\hline 3 & 3 & 1 & 4 \\
\hline 4 & 4 & 1 & 5 \\
\hline 5 & 7 & 1 & 8 \\
\hline 6 & 4 & 1 & 5 \\
\hline 7 & 2 & 0 & 2 \\
\hline 8 & 4 & 1 & 5 \\
\hline 9 & 3 & 1 & 4 \\
\hline 10 & 6 & 0 & 6 \\
\hline 11 & 10 & 2 & 12 \\
\hline Totals: & 43 & 8 & 51 \\
\hline
\end{tabular}

In this table, the "Total Assmt" column for each week lists when all of the assignments are required to be graded by the instructor. The "Total Exams" column for each week lists when all of the exams are required to be graded by the instructor. The "Weekly Total" shows the combined grading totals. The "Totals:" at the bottom of this table shows the combined item totals for the instructors by the end of the quarter.

Moving on to Table 6, Total Quarter Instructor Course Grading, all of the "Total Grading" from the bottom of Table 2, Summarized Student/Instructor Course Assignment Planning are added together with all of the "Total Grading" from the bottom of Table 3, Summarized Student/Instructor Course Exam Planning. In this table, just the shortened name is given for each class is given with the combined totals.

Table 6, Total Quarter Instructor Course Grading

\begin{tabular}{|l|r|}
\hline $\begin{array}{l}\text { Total Quarter } \\
\text { Class }\end{array}$ & Grading \\
\hline TECH 320 & 512 \\
\hline TECH 330 & 180 \\
\hline TECH 393 & 232 \\
\hline TECH 403 & 280 \\
\hline TECH 452 & 259 \\
\hline TECH 454 & 190 \\
\hline TECH 495 & 28 \\
\hline Grand Total: & 1,681 \\
\hline
\end{tabular}


In this table, we are looking at the end of the quarter total of workload to be graded by the instructor for each class. The final numbers, shown by the "Grand Total", reveal a startling number of 1,681 items that need to be graded with the classes that were reviewed by this method.

\section{Method 1 and Method 2 Course Differences}

Differences in the same named classes in both methods show a change in how these classes were altered in order to effect a change to both the student's workload and the instructors grading load. In method 1 , the courses contained the traditional mid-term and finals. In method 2, the same courses had the mid-term and finals removed from the courses. These were replaced in each course by expanding the other types of student work required in each course.

In the TECH 320 Non-Metallics course, the four quizzes were upgrade to four exams that covered all of the material traditionally covered by the mid-term and final. In the TECH 452 Engineering Economics course, the homework assignments were altered to insure retention of knowledge that was traditionally checked for in the mid-term and final. In the TECH 452 Engineering Economics course, the mid-term and final were replaced with more student-centered active involvement projects.

\section{Method 1 and Method 2 Comparison}

Method 1 looked at the workload primarily from the instructor's viewpoint. The three selected classes would represent a full workload for one instructor, for one quarter, in the Engineering and Design Department. It creates a good roadmap for planning what needs to be done on a weekly basis in order for the instructor to stay current with each of the three classes. It also points out two severe grading peeks at week six and week ten. The peak at week six is the harder of the two to handle, because of the requirements the rest of the quarters grading. The peak at week ten is handled as "that large amount of grading" that has historically occurred at the end of the quarter. While it is possible that some students may take all of the these three selected classes from one instructor, what Method 1 does not do is to look at what we are doing to the student's total workload throughout the quarter.

In Method 2, the goal was to look at both the student's and the instructor's workloads. The selected classes represent a broader range of classes that would be available to the students to take during one quarter in the Engineering and Design Department. While an instructor may normally only teach three or four classes, the students in the program will most likely be taking classes from multiple instructors. In situations, where instructors need to teach overloads, this method helps to balance the instructor workload. In addition, this method forces us to look at the possible combinations and interactions when students take a full course load (18 credits) for the quarter. Because of this increased awareness of the combinations, interactions and peak loading, caused by the traditional midterms and finals shown in Method 1, a better understanding is gained of what happens to the student's total workload. In order to help insure the overall success of student learning, a different structure needed to be set up. It is also important to address what is occurring to the instructors, relative to their classroom workload. 
The planning used in Method 2 required coordination between instructors to insure that the assignments and projects were handed out in a staggered methodology across multiple classes. By moving away from midterms and finals, it was possible to diminish the peaks for both the students and the instructors. In realty, the planning insights offered by both methods need to used by each instructor to help them better prepare for themselves and for the students.

\section{Impact on Student Learning}

Various methods of teaching can be used to put the students interests first, as a priority. Faculty members need to consider this when they are arranging the assignments, exams, and other projects for their courses. Rather than concentrating activities together, such as traditional midterms and finals, the student workload can be managed better by distributing them throughout the entire term. For this to work effectively, they also need to share their course timelines with the other faculty members in their department. This pre-planning would spread out due dates and exam dates rather than having multiple events occur on the same day.

For example, when a student has only one exam scheduled on a day, it is highly likely that their performance will be improved over having more than one taking place on the same day. When this leveling of activities is applied to assignments and projects, an improvement in student learning and performance will also likely occur.

In a similar manner, this pre-planning can also help to balance the faculty workload equally across the entire term. This would remove the peaks and valleys of faculty effort that are commonly found during the term while teaching courses. This may even allow additional time for facilitative tasks, evaluative tasks, and even administrative tasks. Prior planning of workload can also lead to a better faculty experience, improved job satisfaction, and better morale. Many faculty members may not be accustomed to this type of course design and smoothing activity, but it is well worth the effort.

\section{Conclusions, Reflections, and the Future}

What instructional planning method is best? The answer is perhaps different for each instructor as a method is selected somewhere along the path of becoming educators. These methods are chosen based on pedagogical methodologies learned or methods used that work in the given moment. Most of the educators in engineering programs are required to have higher-level technical-based degrees, but are not necessarily required to have an advanced educational-based degree. Are there better instructional planning methods to balancing student and instructor workload? Can they improve the outcomes for students and instructors? Are the methods presented in this paper the only possibility? In reality there are actually many other possibilities beyond the time-honored combination of assignments, midterms, and finals. Instructors need to ponder this thought and ask themselves "is the traditional method of delivering course content with the use of mid-terms and finals really the best way to have students learn?"

The Method 2, discussed in this paper has been used in a limited way for one of the programs in the Engineering and Design Department. A review will be conducted to assess its impact and value for both students and the instructors. 


\section{Bibliography}

1. American Mathematical Society. (2012). Balancing Faculty Workload. Retrieved from: http://www.ams.org/profession/leaders/workshops/Hodges.WorkloadIssues2012.pdf

2. Cundy, V., Gibson, D. F., \& Rabern, D. (2001). A Model to Assess and Balance Faculty Workload. Proceedings of the American Society for Engineering Education (ASEE) Conference, Albuquerque, New Mexico, June 24$27,2001$.

3. Houston, D., Meyer, L. H., \& Paewai, S. (2006). Academic Staff Workloads and Job Satisfaction: Expectations and Values in Academe. Journal of Higher Education Policy and Management, 28:1, 17-30.

4. Megis, J. (2012). MikroTik Router OS Workshop Load Balancing Best Practice. Retrieved from: http://mum.mikrotik.com/presentations/PL12/Load_Balancing_workshop.pdf

5. Soliman, I. \& Soliman, H, (1997). Academic Workload and Quality. Change: The Magazine of Higher Learning, 22:2, 135-157.

6. Winkler, A. M. (1992). The Faculty Workload Question. Change: The Magazine of Higher Learning, 24:4, 3641. 